\title{
Determination of Secant Moduli of Agbelouve Silty Sand Stabilized With Cement Used as a Roadway Layer in Togo
}

\author{
Abalo P'kla, Yawovi Mawuénya Xolali Dany Ayité
}

\begin{abstract}
The soil stabilization use is necessary in the presence of lesser quality soils. This stabilization has the effect of modifying the soils properties, in particular the strain modulus. For road dimensioning using rational method, it is necessary to know secant modulus of the soil which is not often done in Togo. In this paper, it is determined the secant modulus at different ages of silty sand stabilized with cement at different rates. For this, specimen of silty sand stabilized with cement at rates of 2.5; 3.5 and $4.5 \%$ are subjected to the Modified Proctor test and measurement of compressive strength with strain measurement to estimate the modulus at 7, 28, 60 and 90 days of age. The results show that moduli increase with age and cement rate. From different correlations, we estimate the dimensioning modulus of Agbélouvé silty sand stabilized with cement. These estimated moduli allow saying that the cement rate studied are satisfactory from the modulus viewpoint. This study completes the information on Togolese materials needed for road dimensioning by rational methods.
\end{abstract}

Keywords: cement stabilization, dimensioning modulus, secant modulus, silty sand, strain.

\section{INTRODUCTION}

$S_{\text {tabilization is a soil improvement technique that consists }}$ of a mixture of this soil and hydraulic binder (cement and / or lime) or clay or hydrocarbon binder (bitumen) to improve this soil performance with its behavior modification: the soil becomes more or less long term semi-rigid [1]-[3]. It is often considered in the presence of soils with characteristics lower than those required by the specifications. This improvement is increasingly being considered in Togo because of the increasing scarcity of good quality natural materials.

For road dimensioning by rational methods (through ALIZE software for example), in addition to traffic data, length of life and supporting soil bearing, it is necessary to know borrow materials characteristic like: tensile strength, CBR

Revised Manuscript Received on December 30, 2019.

* Correspondence Author

Abalo P'kla*, Department of Civil Engineering, Engineers High National School of University of Lome, Lome, Togo.

Email: jeanpierrepkla@gmail.com

Yawovi Mawuénya Xolali Dany Ayité, Department of Civil Engineering Engineers, High National School of University of Lome, Lome, Togo. Email: danyayite@gmail.com

(C) The Authors. Published by Blue Eyes Intelligence Engineering and Sciences Publication (BEIESP). This is an open access article under the CC BY-NC-ND license (http://creativecommons.org/licenses/by-nc-nd/4.0/) index, fatigue resistance and modulus [4]. Information on Togolese materials characteristics is scarce and the limited information available concern only tensile strength and CBR index but not modulus. To evaluate modulus, the relationship (1) given below by the pavement design guide for tropical countries [4] is often used:

$$
\mathrm{E}=\mathrm{K} \times \mathrm{CBR}(1)
$$

Where $\mathrm{E}$ is the dimensioning modulus

$\mathrm{K}$ is a coefficient between 5 and 10 and usually taken as 5 CBR is the CBR index after 4 days of immersion.

In this work, it is envisaged the strain modulus determination of Agbélouvé silty sand stabilized with 2.5; 3.5 and 4.5\% cement (dosage commonly used in Togo).

\section{MATERIALS AND METHOD}

The silty sand used in this study is taken from Agbélouvé quarry, located $60 \mathrm{~km}$ north of Lomé, the capital of Togo. The binder used is CPJ35 cement from CIMTOGO of Togo. Table I and Fig. 1 show silty sand identification tests results. The material contents $13 \%$ of fines and its sand gleichwert is 28. It can be used as a sub-base course $(\mathrm{CBR}>5)$ or as a base course for light traffic (CBR> 25) [4].

Table- I: Studied silty sand characteristics

\begin{tabular}{|c|c|c|c|c|c|}
\hline $\begin{array}{c}\text { Passed-by } \\
\leq \mathbf{8 0 \mu \mathrm { m }} \\
(\%)\end{array}$ & $\begin{array}{c}\text { Passed-by } \\
\leq 2 \mathrm{~mm} \\
(\%)\end{array}$ & $\begin{array}{c}\text { Sand } \\
\text { gleichwert } \\
\text { with } \\
\text { Piston }\end{array}$ & $\begin{array}{c}\text { Proctor } \\
\text { optimum } \\
\text { density } \\
\left(\mathrm{g} / \mathrm{cm}^{3}\right)\end{array}$ & $\begin{array}{c}\text { Proctor } \\
\text { optimum } \\
\text { water } \\
\text { content } \\
(\%)\end{array}$ & $\begin{array}{c}\text { CBR at } 4 \\
\text { days of } \\
\text { imbibition } \\
(95 \% \\
\text { OPM) }\end{array}$ \\
\hline 13 & 100 & 28 & 2,00 & 5,8 & 26 \\
\hline
\end{tabular}

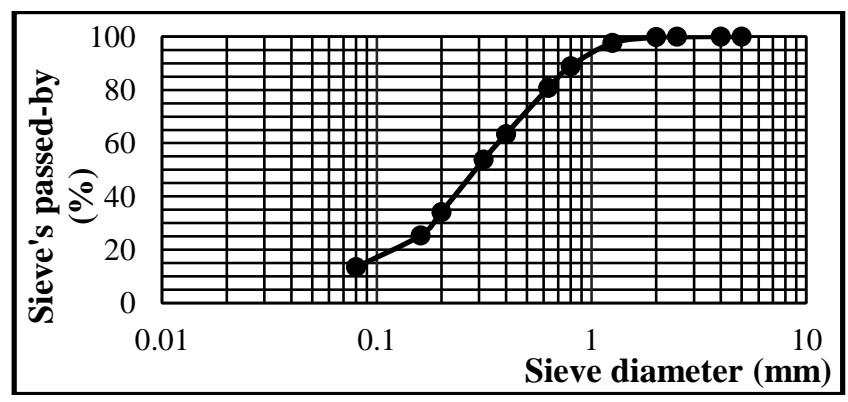

Fig. 1.Studied silty sand grading curve

To achieve our objective, we proceeded to the cement mass variation compared to the silty sand dry mass at rates of $2.5 \%$, $3.5 \%$ and $4.5 \%$. 
Then, we determine the compaction optimal water content by the Proctor test Modified according to standard NF P 94-093 [5] and the compressive stress with strain measurement according to standard NF EN 13286-41 [6]. From these measurements, we determine the moduli [6]-[8].

The simple compression tests were carried out using a semi-automatic CBR press at a speed of $1.27 \mathrm{~mm} / \mathrm{min}$ (Fig. 2) on cylindrical specimens with a height of $12.75 \mathrm{~cm}$ and a diameter of 15.2. $\mathrm{cm}$ is a slenderness of 0.84 . The test piece is placed between the piston of the press whose lower plate is movable. The piston of the press being about $5 \mathrm{~cm}$ in diameter, a rigid disk is placed on the upper face of the test piece to evenly distribute the force over its entire surface. A torque ring with a capacity of $100 \mathrm{kN}$ is used to measure the compressive force by means of the Ring Force-strain calibration curve. Comparator microphones graduated to $1 / 100 \mathrm{~mm}$ are fixed on the press moving plate to measure the longitudinal displacement of the test specimen. The test is stopped when the force measured by the sensor has decreased by at least $10 \%$ of the greatest measured force. This makes sure that we have gone to the test piece break. Throughout this test, displacement is read on the comparator placed on specimen surface.

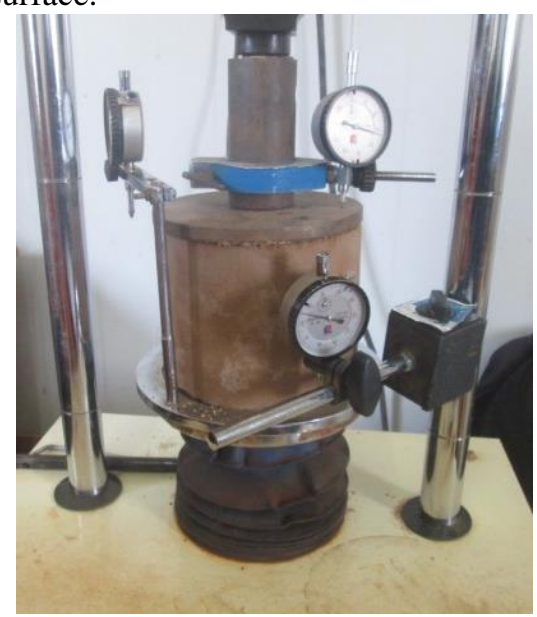

Fig. 2.Device of the compression test

The strain is the ratio between displacement and specimen height measured before the test and the stress is determined by making the ratio between the applied force and the specimen surface S:

$$
\begin{gathered}
\varepsilon=\mathrm{d} / \mathrm{h} \\
\sigma=\mathrm{F} / \mathrm{S}
\end{gathered}
$$

The tests are performed on specimen at 7, 28, 60 and 90 days of age. The stabilized materials are kept for 7 days in a plastic film and the rest of the time at ambient temperature in the room [6].

Where d denotes displacement (mm)

h, specimen height (mm)

$\varepsilon$, strain (dimensionless)

$\mathrm{F}$, applied force $(\mathrm{N})$

$\mathrm{S}$, specimen surface of the test piece $\left(\mathrm{mm}^{2}\right)$

$\sigma$, stress (MPa).

In order to make a comparative study between the different moduli used by finite element calculation software to characterize the stiffness of the material, we have chosen to determine 4 types of moduli:

- The secant modulus at $30 \%$ of the breaking load

- The secant modulus at $50 \%$ of the breaking load

- The secant modulus at break

- The maximum modulus.

The secant moduli at $30 \%$ and at $50 \%$ of the breaking load are respectively given by the following formulas:

$$
\begin{aligned}
& \mathrm{E}_{30}=0.3 \sigma_{c} / \varepsilon_{30} \\
& \mathrm{E}_{50}=0.5 \sigma_{c} / \varepsilon_{50}
\end{aligned}
$$

Where $\sigma_{\mathrm{c}}$ denotes breaking stress (MPa)

$\varepsilon_{30}$ and $\varepsilon_{50}$, the deformations corresponding to $30 \%$ and $50 \%$ of the breaking load read on the stress-strain curve

$\mathrm{E}_{30}$ and $\mathrm{E}_{50}$, respectively, strain moduli at $30 \%$ and $50 \%$ of the breaking load (MPa)

The secant modulus at break is defined as the slope of the line connecting the origin to the ordinate point $\sigma \mathrm{c}$. It is given by the following formula:

$$
\mathrm{E}=\sigma_{\mathrm{c}} / \varepsilon_{\mathrm{C}}
$$

Where $\sigma_{\mathrm{c}}$ denotes breaking stress (MPa)

$\varepsilon_{\mathrm{c}}$, strain at break

$\mathrm{E}$, strain modulus at break (MPa).

The maximum modulus is determined by following the line of greatest slope of the stress-strain curve as illustrated in Fig. 3.

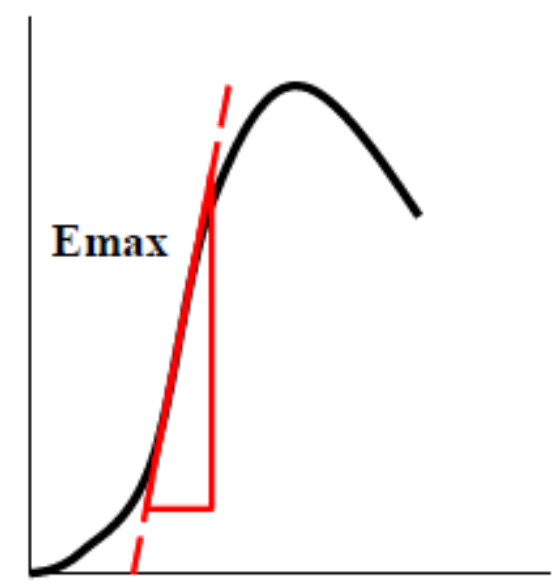

Fig. 3.Maximum modulus determination method

\section{RESULTS AND DISCUSSIONS}

Table II presents the results of Modified Proctor tests performed on stabilized silty sand. There is a slight increase in water content and optimum density depending on the cement content. Indeed, Proctor's optimum density increases with cement content of $2.05 \mathrm{~g} / \mathrm{cm}^{3}$ for $2.5 \%$ cement at $2.08 \mathrm{~g} / \mathrm{cm}^{3}$ for 3.5 and $4.5 \%$ cement, as well as in optimal water production (Table II). It is at these respective water contents that the specimens are manufactured for the mechanical tests. 
Table- II: Results of the Proctor test on silty sand stabilized at different cement rates

\begin{tabular}{|c|c|c|}
\hline $\begin{array}{c}\text { Cement rate } \\
(\%)\end{array}$ & $\begin{array}{c}\text { Proctor optimum } \\
\text { density }\left(\mathrm{g} / \mathrm{cm}^{3}\right)\end{array}$ & $\begin{array}{c}\text { Proctor optimum } \\
\text { water content (\%) }\end{array}$ \\
\hline 2.5 & 2.05 & 5.9 \\
\hline 3.5 & 2.08 & 6.0 \\
\hline 4.5 & 2.08 & 6.1 \\
\hline
\end{tabular}

The strain and stress tests results are presented in Tables III to VI. Each result is the average of three values.

Table- III: Strain and stress at $\mathbf{7}$ days of age according to cement rate

\begin{tabular}{|c|c|c|c|c|c|}
\hline \multicolumn{2}{|c|}{ Cement rate: $2.5 \%$} & \multicolumn{2}{c|}{ Cement rate: $3.5 \%$} & \multicolumn{2}{c|}{ Cement rate: 4.5\% } \\
\hline Strain $\left(10^{-6}\right)$ & Stress (MPa) & Strain $\left(10^{-6}\right)$ & Stress (MPa) & Strain $\left(10^{-6}\right)$ & Stress (MPa) \\
\hline 0 & 0,0000 & 0,0000 & 0,0000 & 0,0000 & 0,0000 \\
\hline 1,96 & 0,1320 & 19,600 & 0,0953 & 19,600 & 0,1027 \\
\hline 3,92 & 0,3080 & 39,200 & 0,3887 & 39,200 & 0,4327 \\
\hline 5,88 & 0,4547 & 58,800 & 0,7490 & 58,800 & 0,9617 \\
\hline 7,84 & 0,6977 & 78,400 & 10,057 & 78,400 & 13,283 \\
\hline 9,80 & 0,8793 & 98,000 & 13,430 & 98,000 & 17,617 \\
\hline 10,51 & 10,000 & 117,600 & 16,510 & 117,600 & 20,183 \\
\hline & & 145,867 & 20,867 & 137,300 & 23,720 \\
\hline & & & & 147,050 & 27,550 \\
\hline
\end{tabular}

Table- IV: Strain and stress at $\mathbf{2 8}$ days of age according to cement rate

\begin{tabular}{|c|c|c|c|c|c|}
\hline \multicolumn{2}{|c|}{ Cement rate: $2.5 \%$} & \multicolumn{2}{c|}{ Cement rate: $3.5 \%$} & \multicolumn{2}{c|}{ Cement rate: $4.5 \%$} \\
\hline \multirow{2}{*}{ Strain $\left(10^{-6}\right)$} & Stress (MPa) & Strain $\left(10^{-6}\right)$ & Stress (MPa) & Strain $\left(10^{-6}\right)$ & Stress (MPa) \\
\hline 0,0000 & 0,0000 & 0,0000 & 0,0000 & 0,0000 & 0,0000 \\
\hline 0,2000 & 0,0880 & 0,2000 & 0,1173 & 0,2000 & 0,1540 \\
\hline 0,3900 & 0,1907 & 0,3900 & 0,2420 & 0,3900 & 0,3007 \\
\hline 0,5900 & 0,3153 & 0,5900 & 0,3813 & 0,5900 & 0,4693 \\
\hline 0,7800 & 0,4547 & 0,7800 & 0,5503 & 0,7800 & 0,6903 \\
\hline 0,9800 & 0,6093 & 0,9800 & 0,7490 & 0,9800 & 0,9543 \\
\hline 11,800 & 0,7417 & 11,800 & 0,9763 & 11,800 & 12,110 \\
\hline 13,700 & 0,9030 & 13,700 & 12,110 & 13,700 & 14,530 \\
\hline 15,700 & 10,717 & 15,700 & 14,310 & 15,700 & 17,030 \\
\hline 17,600 & 12,623 & 17,600 & 16,663 & 17,600 & 19,747 \\
\hline 19,600 & 14,457 & 19,600 & 19,307 & 19,600 & 22,533 \\
\hline 21,967 & 16,577 & 21,600 & 22,167 & 21,600 & 25,173 \\
\hline 23,500 & 17,185 & 23,500 & 25,173 & 23,500 & 27,817 \\
\hline 25,500 & 17,180 & 25,500 & 27,593 & 25,500 & 31,050 \\
\hline 27,500 & 18,300 & 27,500 & 30,243 & 27,500 & 34,130 \\
\hline & & 29,400 & 32,517 & 29,400 & 36,697 \\
\hline & & 31,400 & 34,790 & 31,400 & 39,340 \\
\hline & & 33,300 & 36,403 & 33,300 & 42,060 \\
\hline & & 35,300 & 37,650 & 35,300 & 44,773 \\
\hline & & 37,300 & 38,603 & 37,300 & 46,387 \\
\hline & & 39,200 & 40,137 & 39,200 & 47,840 \\
\hline & & 40,400 & 41,200 & 41,200 & 49,100 \\
\hline & & & & 43,100 & 50,640 \\
\hline & & & & 45,100 & 52,050 \\
\hline
\end{tabular}


Table- V: Strain and stress at $\mathbf{6 0}$ days of age according to cement rate

\begin{tabular}{|c|c|c|c|c|c|}
\hline \multicolumn{2}{|c|}{ Cement rate: $2.5 \%$} & \multicolumn{2}{|c|}{ Cement rate: 3.5\% } & \multicolumn{2}{|c|}{ Cement rate: $4.5 \%$} \\
\hline Strain $\left(10^{-6}\right)$ & Stress (MPa) & Strain $\left(10^{-6}\right)$ & Stress (MPa) & Strain $\left(10^{-6}\right)$ & Stress (MPa) \\
\hline 0,0000 & 0,0000 & 0,0000 & 0,0000 & 0,0000 & 0,0000 \\
\hline 0,2000 & 0,0953 & 0,2000 & 0,1247 & 0,2000 & 0,1467 \\
\hline 0,3900 & 0,2053 & 0,3900 & 0,2567 & 0,3900 & 0,2713 \\
\hline 0,5900 & 0,3520 & 0,5900 & 0,4327 & 0,5900 & 0,4620 \\
\hline 0,7800 & 0,5283 & 0,7800 & 0,6683 & 0,7800 & 0,7417 \\
\hline 0,9800 & 0,6973 & 0,9800 & 0,9177 & 0,9800 & 10,497 \\
\hline 11,800 & 0,9030 & 11,800 & 12,110 & 11,800 & 13,797 \\
\hline 13,700 & 11,010 & 13,700 & 15,853 & 13,700 & 17,840 \\
\hline 15,700 & 13,210 & 15,700 & 19,380 & 15,700 & 21,213 \\
\hline 17,600 & 15,340 & 17,600 & 22,680 & 17,600 & 24,293 \\
\hline 19,600 & 17,617 & 19,600 & 26,057 & 19,600 & 27,743 \\
\hline 21,600 & 19,890 & 21,600 & 28,847 & 21,600 & 31,123 \\
\hline 23,500 & 22,167 & 23,500 & 32,150 & 23,500 & 34,277 \\
\hline 25,500 & 23,853 & 25,500 & 34,863 & 25,500 & 39,267 \\
\hline 27,500 & 24,750 & 27,500 & 37,430 & 27,500 & 42,427 \\
\hline 29,400 & 26,900 & 29,400 & 40,443 & 29,400 & 45,873 \\
\hline & & 31,400 & 42,647 & 31,400 & 48,953 \\
\hline & & 33,300 & 45,800 & 33,300 & 51,673 \\
\hline & & 35,300 & 48,293 & 35,300 & 54,683 \\
\hline & & 37,300 & 50,867 & 37,300 & 57,543 \\
\hline & & 39,467 & 53,787 & 39,200 & 59,593 \\
\hline & & 40,800 & 55,065 & 41,333 & 61,723 \\
\hline & & 41,600 & 56,675 & & \\
\hline
\end{tabular}

Table- VI: Strain and stress at 90 days of age according to cement rate

\begin{tabular}{|c|c|c|c|c|c|}
\hline \multicolumn{2}{|c|}{ Cement rate: $2.5 \%$} & \multicolumn{2}{c|}{ Cement rate: $3.5 \%$} & \multicolumn{2}{c|}{ Cement rate: $4.5 \%$} \\
\hline Strain $\left(10^{-6}\right)$ & Stress (MPa) & Strain $\left(10^{-6}\right)$ & Stress (MPa) & Strain $\left(10^{-6}\right)$ & Stress (MPa) \\
\hline 0,0000 & 0,0000 & 0,0000 & 0,0000 & 0,0000 & 0,0000 \\
\hline 0,2000 & 0,1247 & 0,2000 & 0,1393 & 0,2000 & 0,1540 \\
\hline 0,3900 & 0,3007 & 0,3900 & 0,3667 & 0,3900 & 0,3887 \\
\hline 0,5900 & 0,5280 & 0,5900 & 0,6093 & 0,5900 & 0,7270 \\
\hline 0,7800 & 0,8297 & 0,7800 & 0,9763 & 0,7800 & 11,817 \\
\hline 0,9800 & 11,010 & 0,9800 & 14,090 & 0,9800 & 16,807 \\
\hline 11,800 & 14,677 & 11,800 & 18,717 & 11,800 & 22,533 \\
\hline 13,700 & 19,087 & 13,700 & 23,927 & 13,700 & 28,700 \\
\hline 15,700 & 23,120 & 15,700 & 29,947 & 15,700 & 35,230 \\
\hline 17,600 & 28,110 & 17,600 & 35,450 & 17,600 & 41,250 \\
\hline 19,600 & 32,150 & 19,600 & 40,590 & 19,600 & 46,827 \\
\hline 21,600 & 34,727 & 21,600 & 45,947 & 21,600 & 51,747 \\
\hline 23,233 & 36,163 & 23,500 & 50,717 & 23,500 & 55,930 \\
\hline 24,300 & 37,430 & 25,500 & 55,123 & 25,500 & 59,820 \\
\hline & & 27,500 & 59,523 & 27,500 & 63,857 \\
\hline & & 29,400 & 62,753 & 29,400 & 67,307 \\
\hline & & 31,400 & 65,987 & 31,400 & 70,533 \\
\hline & & 33,300 & 69,653 & 33,300 & 73,543 \\
\hline & & 35,300 & 72,957 & 35,300 & 76,557 \\
\hline & & 36,500 & 73,985 & 36,767 & 78,610 \\
\hline & & & & 39,200 & 80,370 \\
\hline & & & & & \\
\hline & & & & & \\
\hline & & & & & \\
\hline
\end{tabular}

Published By:

Blue Eyes Intelligence Engineering 
From the results of Tables III to VI, we plot the stress-strain curves (Fig. 4 to 7 ) for each mixture and at each age to determine the different secant moduli.

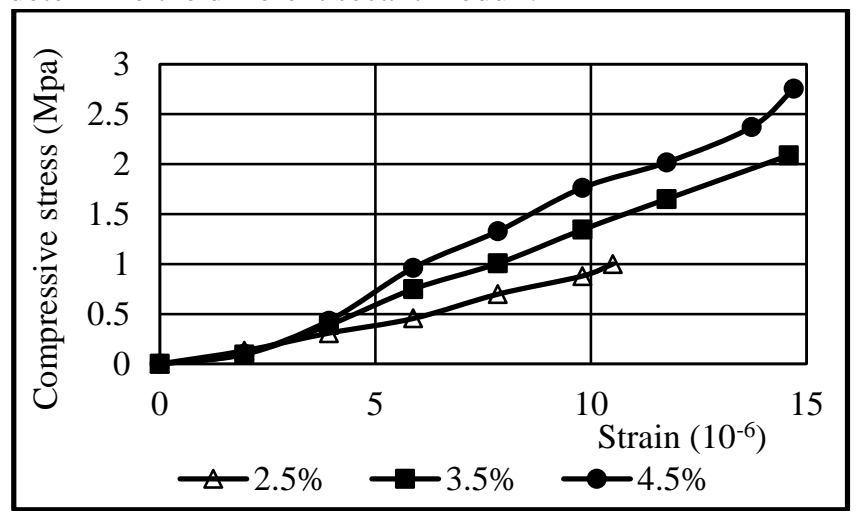

Fig. 4.Stress - strain curve at 7 days

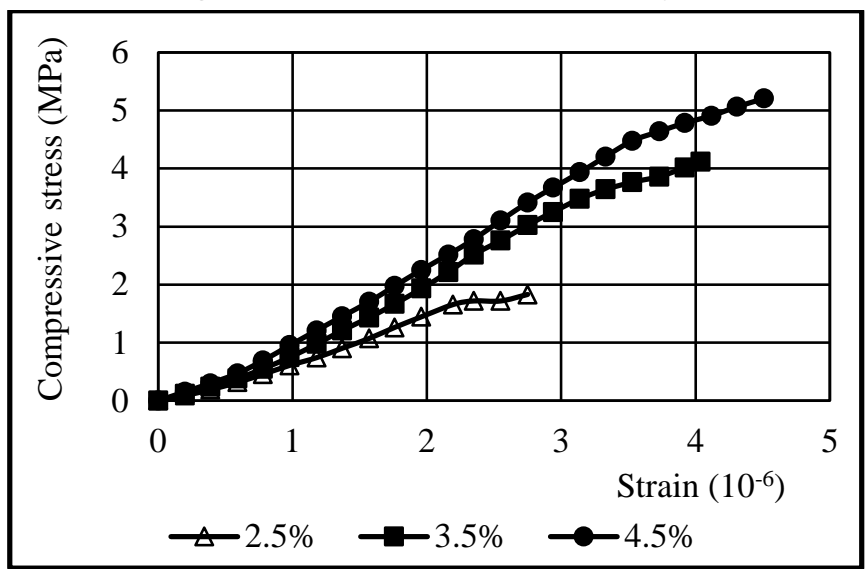

Fig. 5.Stress - strain curve at 28 days

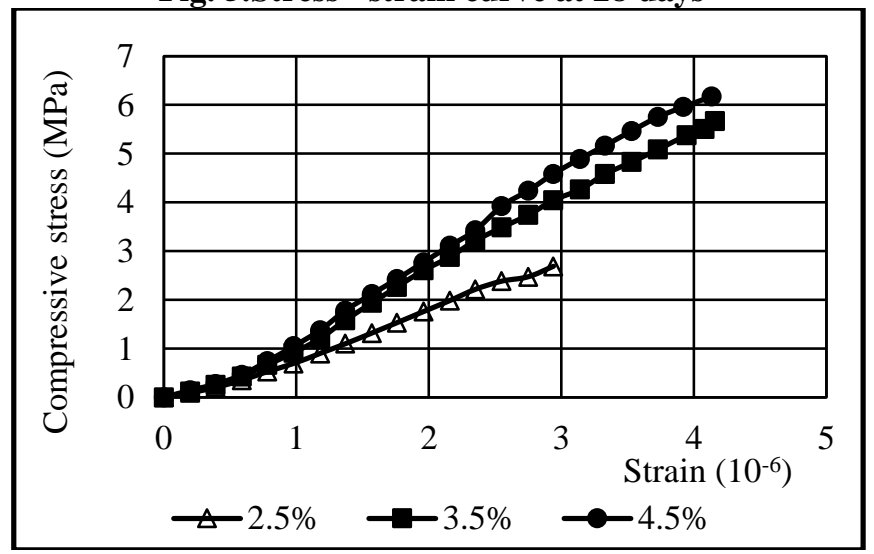

Fig. 6.Stress - strain curve at 60 days

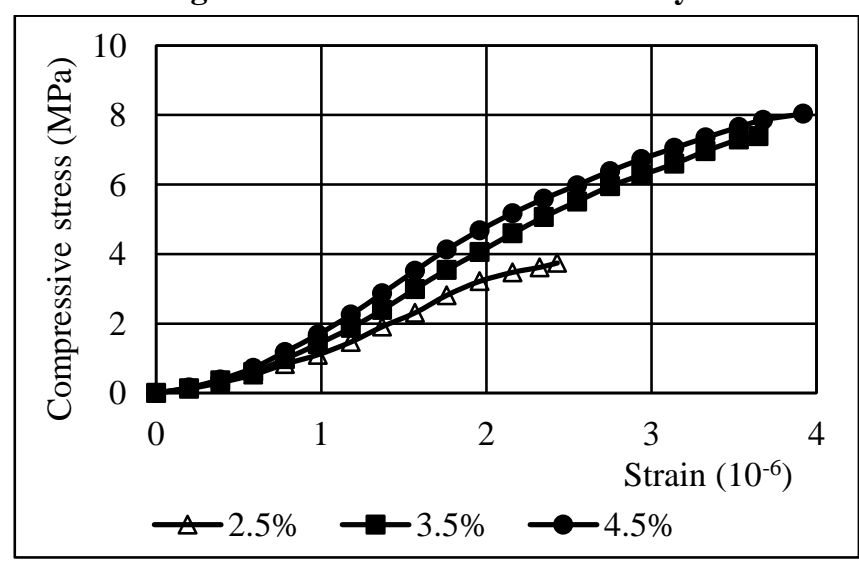

Fig. 7.Stress - strain curve at 90 days

The moduli calculation results are presented in Table VII.

Table- VII: Secant moduli according to age and cement rate

\begin{tabular}{|c|c|c|c|c|c|}
\hline \multirow{4}{*}{$\begin{array}{c}\text { Age } \\
\text { (days) }\end{array}$} & $\begin{array}{c}\text { Cement } \\
\text { rate } \\
\text { (\%) }\end{array}$ & $\begin{array}{c}\text { Secant } \\
\text { modulus } \\
\text { at 30\% } \\
\text { of the } \\
\text { breaking } \\
\text { load } \\
\text { (MPa) }\end{array}$ & $\begin{array}{c}\text { Secant } \\
\text { modulus } \\
\text { at 50\% } \\
\text { of the } \\
\text { breaking } \\
\text { load } \\
\text { (MPa) }\end{array}$ & $\begin{array}{c}\text { Secant } \\
\text { modulus } \\
\text { at break } \\
\text { (MPa) }\end{array}$ & $\begin{array}{c}\text { Maximum } \\
\text { modulus } \\
\text { (MPa) }\end{array}$ \\
\hline \multirow{4}{*}{7} & 2.5 & 80 & 81 & 95 & 122 \\
\cline { 2 - 6 } & 3.5 & 119 & 130 & 143 & 210 \\
\cline { 2 - 6 } 28 & 4.5 & 161 & 184 & 189 & 247 \\
\hline \multirow{4}{*}{60} & 2.5 & 614 & 662 & 742 & 923 \\
\cline { 2 - 6 } & 3.5 & 904 & 1011 & 1026 & 1327 \\
\cline { 2 - 7 } & 4.5 & 1056 & 1171 & 1182 & 1536 \\
\cline { 2 - 6 } & 2.5 & 737 & 853 & 952 & 1091 \\
\hline \multirow{3}{*}{90} & 4.5 & 1183 & 1348 & 1368 & 1739 \\
\cline { 2 - 6 } & 2.5 & 1328 & 1428 & 1494 & 1876 \\
\cline { 2 - 6 } & 3.5 & 1718 & 2040 & 2055 & 2795 \\
\hline
\end{tabular}

From this table, we deduce, for each age, the variation curves of the moduli according to the cement rate illustrated in Fig. 8 to 11 .

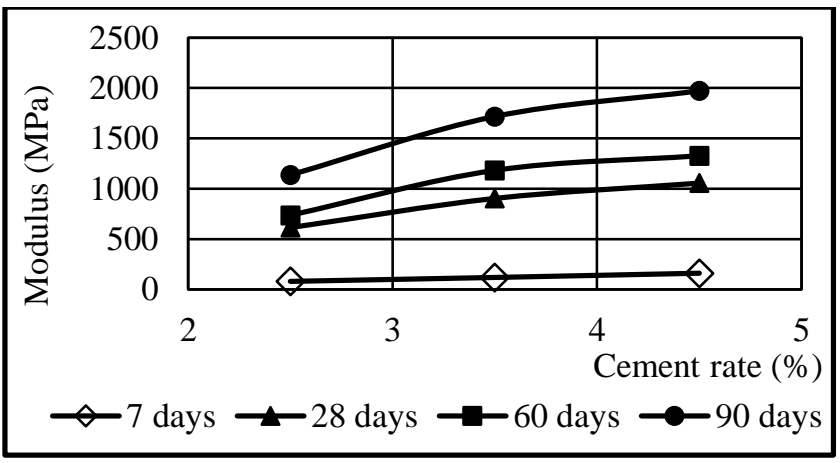

Fig. 8.Secant modulus at $30 \%$ of breaking load evolution as a cement rate function

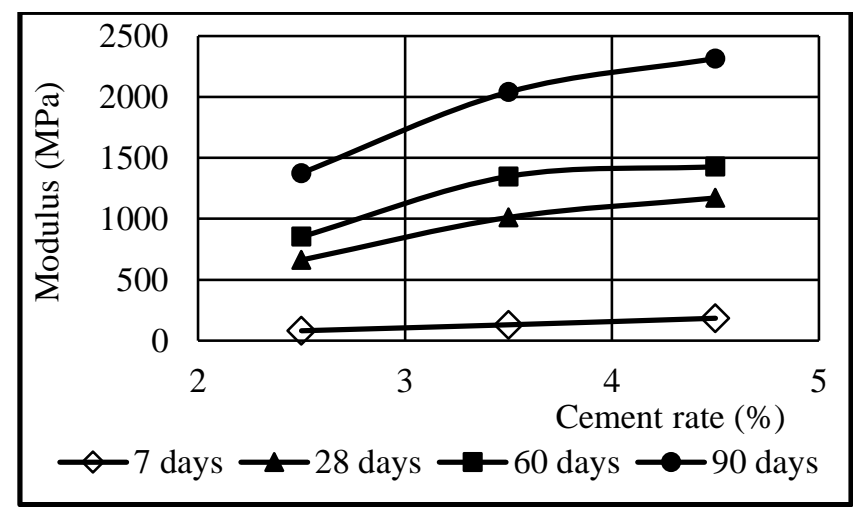

Fig. 9.Secant modulus at $50 \%$ of breaking load evolution as a cement rate function

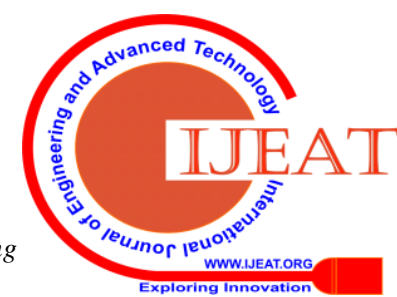




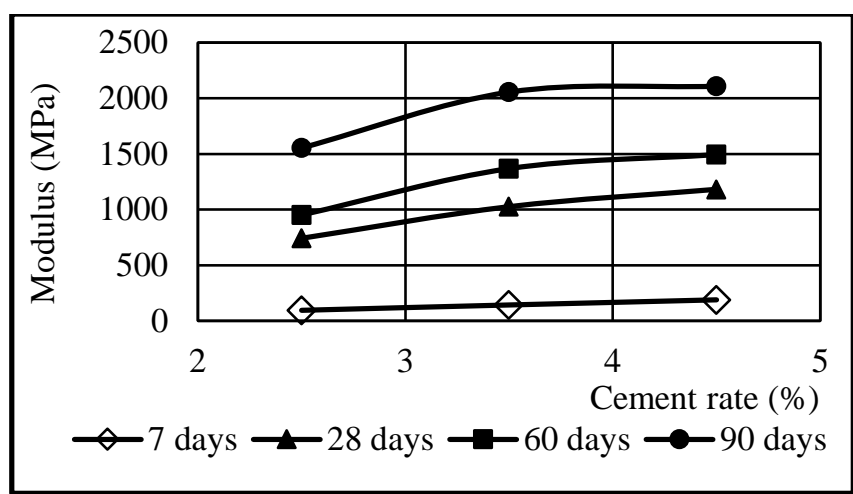

Fig. 10. Secant modulus at break evolution as a cement rate function

Fig. 11. Maximum modulus evolution as a cement rate function

In Fig. 8 to 11, it is noted that moduli increase with the cement dosage:

- for moduli at $30 \%$ of the breaking load, the increase for the $3.5 \%$ dosage compared to the $2.5 \%$ dosage is of the order of $47 \%$ to $61 \%$ while the increase for the $4.5 \%$ dosage compared to the dosage of $3.5 \%$ is in the range of $12 \%$ to $36 \%$;

- the increase of moduli at $50 \%$ of the breaking load for the $3.5 \%$ dosage compared to the $2.5 \%$ dosage is of the order of $48 \%$ to $61 \%$ whereas that of specimens dosed at $4.5 \%$ relative to the test pieces at $3.5 \%$ is in the range of 6 to $41 \%$;

- the gain for the modulus at break of specimens dosed at $3.5 \%$ with respect to specimens dosed at $2.5 \%$ is of the order of $32 \%$ to $50 \%$ while that of specimens dosed at $4.5 \%$ with respect to specimens dosed at 3.5\% is in the range of $3 \%$ to $32 \%$;

- the maximum modulus of specimens dosed at 3.5\% with respect to specimens dosed at $2.5 \%$ increases is of the order of $22 \%$ to $73 \%$ whereas that of specimens dosed at $4.5 \%$ with respect to specimens dosed at $3.5 \%$ has an increase between $8 \%$ and $18 \%$.

These results show that at the same age, despite the same variation rate of cement (1\%), the rate of moduli increase between specimens stabilized at 3.5\% compared to those stabilized at $2.5 \%$ is significantly higher than the rate of moduli increase between specimens stabilized at $4.5 \%$ compared with those stabilized at 3.5\%: this can be explained by the fact that the dry manufacture density of specimens stabilized at $3.5 \%$ is closer to that of specimens stabilized at $4.5 \%$ than that of specimens stabilized at 2.5\%.

From Table VII, we plot in Figures 12 to 15, for each cement dosage, moduli variation curves as a function of age.
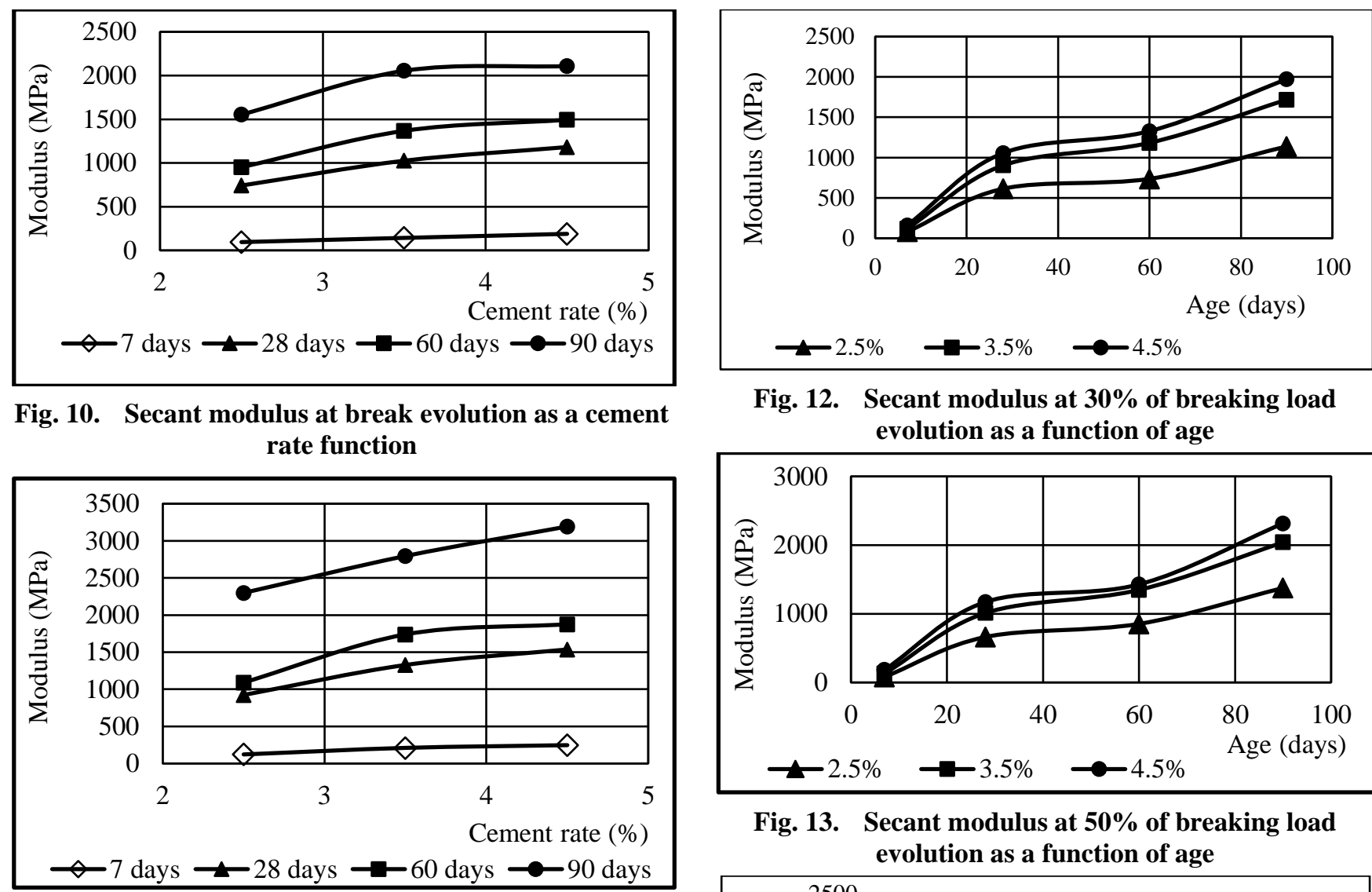

Fig. 12. Secant modulus at $30 \%$ of breaking load evolution as a function of age

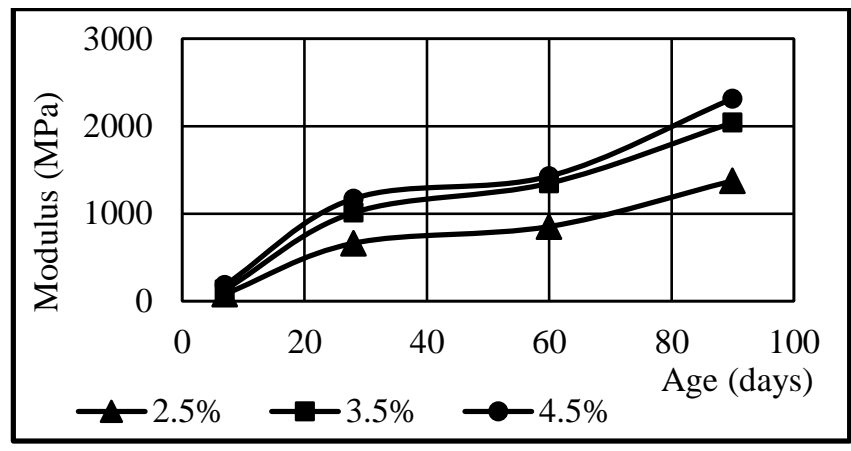

Fig. 13. Secant modulus at $50 \%$ of breaking load evolution as a function of age

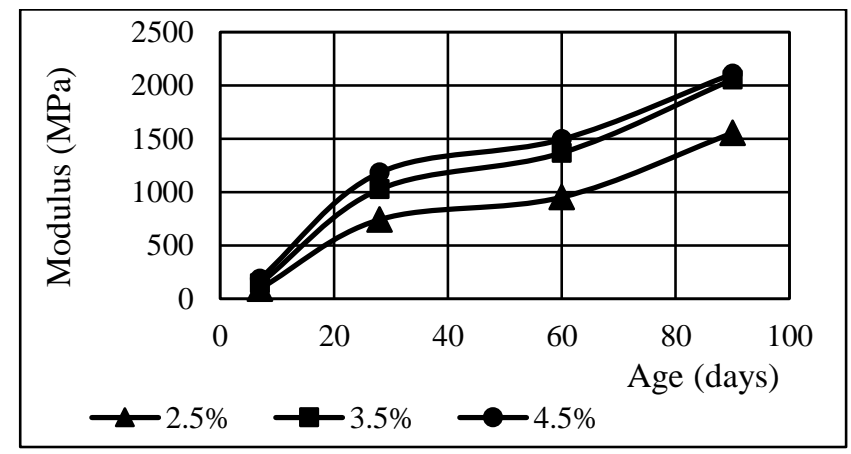

Fig. 14. Secant modulus at break evolution as a function of age

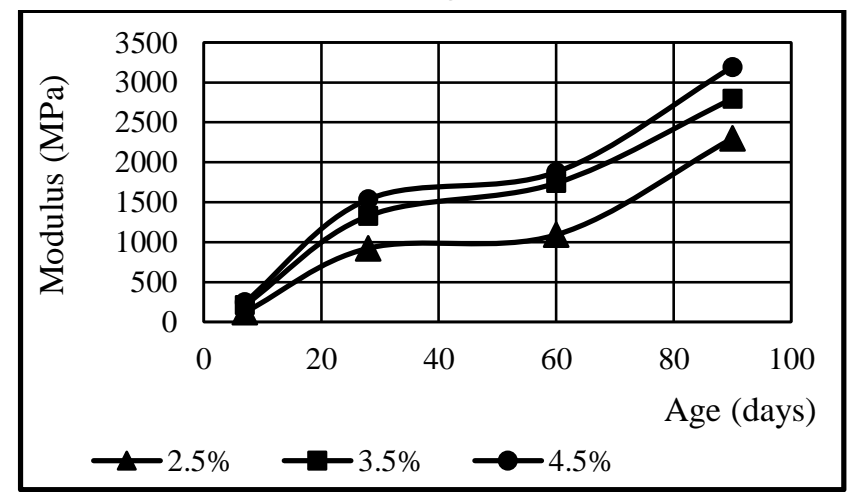

Fig. 15. Maximum modulus evolution as a function of age

Moduli values recorded at 7 days are very low; this is explained by a fairly large deformation obtained and certainly due to a rather slow hardening during the phenomenon of cement setting. 
There is a rapid increase in modulus between 7 and 28 days (more than 5 times the modulus at 7 days) which is explained by an increase in resistance following the phenomenon of setting and hardening of the cement which is almost complete at 28 days. This also explains the fact that beyond 28 days the rate of modulus increase is relatively low:

- indeed, between 7 and 28 days and depending on the dosage there is an increase in the modulus at $30 \%$ of breaking load of the order of $555 \%$ to $670 \%$ whereas it is $20 \%$ to $31 \%$ between 28 and 60 days and from $45 \%$ to $55 \%$ between 60 and 90 days;

- between 7 and 28 days and depending on the dosage there is an increase in the modulus at $50 \%$ of breaking load of the order of $536 \%$ to $715 \%$ while it is $22 \%$ to $33 \%$ between 28 and 60 days and $52 \%$ to $62 \%$ between 60 and 90 days; - between 7 and 28 days and depending on the dosage there is an increase in the modulus at break of the order of $525 \%$ to $681 \%$ while it is $27 \%$ to $33 \%$ between 28 and 60 days and $41 \%$ to $63 \%$ between 60 and 90 days;

- between 7 and 28 days and depending on the dosage, there is an increase of the maximum modulus of the order of $522 \%$ to $659 \%$ whereas it is $18 \%$ to $31 \%$ between 28 and 60 days and from $60 \%$ to $111 \%$ between 60 and 90 days.

The modulus of elasticity offers many advantages over other index values, such as the AASHTO layer coefficients and the California Bearing Index (CBR), because it directly influences the analytical models used to predict the state of constraints. The modulus values used in pavement design will be deducted from the average values at 360 days. If values are not available at 360 days, the SETRA pavement design and dimensioning guide (LCPC-SETRA, 1994) proposes the following formula for sands-cement allowing to obtain the 360-day modulus from the at 90-days modulus [4]:

$$
\mathrm{E}_{90} / \mathrm{E}_{360}=0.93(8)
$$

From the 360-day modulus, the modulus to be used in pavement design is given, for sand-cements, by [4]:

$$
\mathrm{E}_{\mathrm{dim}}=0.75 \mathrm{E}_{360}(9)
$$

The modulus used in (9) is the 360-days modulus at 30\% of breaking load.

Applying (8) and (9), we obtain Table VIII from data in Table VII. We compare obtained dimensioning moduli to the minimum value of the dimensioning modulus requested in the road projects. In fact, for the materials stabilized with cement, a minimum value of $\mathrm{CBR}=160$ [4] is requested that is means a dimensioning modulus of $800 \mathrm{MPa}$ by application (1).

\begin{tabular}{|c|c|c|c|}
\hline $\begin{array}{c}\text { Cement } \\
\text { rate } \\
(\%)\end{array}$ & $\begin{array}{c}\text { 90-days } \\
\text { modulus at } \\
30 \% \text { of } \\
\text { breaking } \\
\text { load (MPa) }\end{array}$ & $\begin{array}{c}\text { 360-days } \\
\text { modulus at } \\
30 \% \text { of } \\
\text { breaking } \\
\text { load (MPa) }\end{array}$ & $\begin{array}{c}\text { Dimensioning } \\
\text { modulus } \\
(\mathrm{MPa})\end{array}$ \\
\hline 2.5 & 1138 & 1223 & 917 \\
\hline 3.5 & 1718 & 1847 & 1385 \\
\hline 4.5 & 1972 & 2120 & 1590 \\
\hline
\end{tabular}

Table- VIII.360-day and dimensioning moduli

Note that dimensioning moduli obtained for the different rates are higher than the estimated minimum, which means that the cement rate studied are satisfactory from the modulus viewpoint.

\section{CONCLUSION}

The study of the stabilized cemented Agbelouve silty sand presented in this paper consisted in the determination of the modulus at different ages up to 90 days. The objective is the determination of the modulus to be used in the design of roadway by the rational method, in particular via Alize software. For materials used in Togo, this modulus is estimated by empirical formulas that may lead to design errors. For this purpose, the compressive stresses and the strains were determined on specimen made in CBR molds which allowed the determination of moduli at $30 \%$ of breaking load, $50 \%$ of breaking load and at break and the maximum modulus. From the modulus at $30 \%$ of breaking load, the modulus to be used for the design of the pavement layers is determined.

\section{REFERENCES}

1. Little D.N. "Evaluation of Structural Properties of Lime Stabilized Soils and Aggregates: Summary of Findings', National Lime Association, 1999, pp 1-89.

2. Thompson M.R. "Lime Reactivity of Illinois Soils", Journal of the Soil Mechanics and Foundation Divisions. Vol. 92, 1966, pp. 67-92.

3. Thompson MR. Suggested Method of Mixture Design Procedures for Lime-Treated Soils. ASTM Special Technical Publication. 479, 1970, pp. $430-440$.

4. LCPC - SETRA, "Conception et dimensionnement des structures de chaussée, guide technique", 1994

5. French Norm NF P 94-093 "Soils: Investigation and testing Determination of the compaction characteristics of a soil — Standard Proctor test - Modified Proctor test", October 2014.

6. French Norm NF EN 13286-41 "Unbound and hydraulically bound mixtures - Part 41: Test method for the determination of the compressive strength of hydraulically bound mixtures", July 2003

7. French Norm NF EN 13286-43. "Unbound and hydraulically bound mixtures - Part 43: Test method for the determination of the modulus of elasticity of hydraulically bound mixtures', September 2003

8. NF EN 13286-53, "Unbound and hydraulically bound mixtures. Part 53: Methods for the manufacture of test specimens of hydraulically bound mixtures using axial compression", May 2005.

9. Charles K. Kankam, Bismark K. Meisuh, Gnida Sossou, Thomas K. Buabin, "Stress-strain characteristics of concrete containing quarry rock dust as partial replacement of sand", Case Studies in Construction Materials, 7, 2017, pp.66-72, http://dx.doi.org/10.1016/j.cscm.2017.06.004

10. Dipti Ranjan Biswal, Umesh C. Sahoo, Suresh R Dash. Strength and stiffness studies of cement stabilized granular lateritic soil, Conference: International Congress and Exhibition "Sustainable Civil Infrastructures: Innovative Infrastructure Geotechnology"320-336. July 2018. DOI: 10.1007/978-3-319-61902-6_25

\section{AUTHORS PROFILE}

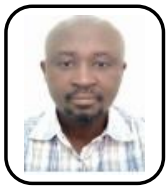

Dr Abalo P'KLA is a professor in Department of Civil Engineering at Engineers High National School of University of Lome, Togo. He has nearly about 6 publications in various journals.

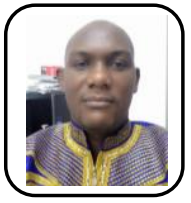

Dr Yawovi M. X. D. AYITE is a professor in Department of Civil Engineering at Engineers High National School of University of Lome, Togo. He has nearly about 12 publications in various journals. 